\title{
Cough as an adverse effect for inhalation pharmaceutical products
}

\author{
Rachel Yoon Kyung Chang ${ }^{1}$, Philip Chi Lip Kwok ${ }^{1}$, Sussan Ghassabian ${ }^{1}$, John Brannan ${ }^{2}$, \\ Heikki Koskela ${ }^{3}$, and Hak-Kim Chan ${ }^{1}$ \\ ${ }^{1}$ The University of Sydney Faculty of Medicine and Health \\ ${ }^{2}$ John Hunter Hospital \\ ${ }^{3}$ Kuopio University Hospital
}

May 5, 2020

\begin{abstract}
Cough is an adverse effect that may hinder the delivery of drugs into the lungs. Chemical or mechanical stimulants activate the transient receptor potential in some airway afferent nerves ( $\mathrm{C}$ or A fibres) to trigger cough. Types of inhaler device and drug, dose, excipients, formulation characteristics including $\mathrm{pH}$, tonicity, aerosol output and particle size may trigger cough by stimulating the cough receptors. Release of inflammatory mediators may increase the sensitivity of the cough receptors to stimulants. The cough-provoking effect of aerosols is enhanced by bronchoconstriction in diseased airways and reduces drug deposition in the target pulmonary regions. In this article, we review the factors by which inhalation products may cause cough.
\end{abstract}

\section{Cough as an adverse effect for inhalation pharmaceutical products}

Running title: Cough and inhalation products

Rachel Yoon Kyung Chang*1, Philip Chi Lip Kwok*1, Sussan Ghassabian*1, John D. Brannan², Heikki Koskela $^{3}$, Hak-Kim Chan ${ }^{1}$

\begin{abstract}
${ }^{1}$ Advanced Drug Delivery Group, Sydney Pharmacy School, Faculty of Medicine and Health, The University of Sydney, Camperdown, NSW, Australia ${ }^{2}$ Department of Respiratory and Sleep Medicine, John Hunter Hospital, Newcastle, NSW, Australia ${ }^{3}$ Unit for Medicine and Clinical Research, Pulmonary Division, Kuopio University Hospital, Kuopio, Finland
\end{abstract}

Corresponding Author : Dr Hak-Kim Chan

Email : kim.chan@sydney.edu.au

Phone : +61293513054

Address : Room S341, Building A15, Science Road, School of Pharmacy, Faculty of Medicine and Health, University of Sydney, Camperdown, NSW, 2006, Australia

*These authors contribute equally to the work. 
Word count: 7073

\title{
Acknowledgements
}

$\mathrm{N} / \mathrm{A}$

\section{Conflict of interest statement}

Dr Brannan receives a $10 \%$ portion of royalties for the sale of AridolTM / OsmohalerTM that are paid to his prior employer, Royal Prince Alfred Hospital. He holds a minimum number shares in the manufacturer Pharmaxis Ltd. In the past has acted as a consultant to Pharmaxis Ltd and the Nth American distributor of AridolTM, Methapharm Pty Ltd

\begin{abstract}
Cough is an adverse effect that may hinder the delivery of drugs into the lungs. Chemical or mechanical stimulants activate the transient receptor potential in some airway afferent nerves ( $\mathrm{C}$ or A fibres) to trigger cough. Types of inhaler device and drug, dose, excipients, formulation characteristics including $\mathrm{pH}$, tonicity, aerosol output and particle size may trigger cough by stimulating the cough receptors. Release of inflammatory mediators may increase the sensitivity of the cough receptors to stimulants. The cough-provoking effect of aerosols is enhanced by bronchoconstriction in diseased airways and reduces drug deposition in the target pulmonary regions. In this article, we review the factors by which inhalation products may cause cough.
\end{abstract}

Keywords : cough; aerosol; adverse effect; inhalation; pharmaceutical products

\section{Abbreviations}

32 -AR $\beta 2$-Adrenergic receptor

ASIC Acid-sensing ion channel

CGRP Calcitonin gene-related peptide

CNS Central nervous system

COPD Chronic obstructive pulmonary disease

DPI Dry powder inhaler

EDTA Ethylenediaminetetraacetic acid

FEV1 Forced expiratory volume in one second

IPF Idiopathic pulmonary fibrosis

LABA Long acting $\beta$-agonist

LAMA Long-acting muscarinic receptor antagonist

MDI Metered dose inhaler

PAH Pulmonary arterial hypertension

PG Prostaglandin

pMDI Pressurised metered dose inhaler

RAR Rapidly adapting receptor

SAR Slowly adapting receptor

TI Technosphere insulin 
TIP Tobramycin inhalation powder

TIS Tobramycin inhalation solution

TRP Transient receptor potential

TRPA1 TRP-ankyrin-1

TRPM8 TRP-melastatin-8

TRPV1 TRP-vanilloid-1

\section{Introduction}

Cough is the most important airway defence mechanism but it is also a major symptom of respiratory diseases, including asthma and chronic obstructive pulmonary disease (COPD) (CDC, 2010). Cough helps to remove potentially harmful substances from entering the respiratory system and clears excessive secretions from the airways. It begins with a brief inspiration (inspiratory phase), followed by expiration against a closed glottis (compression phase), which leads to increased intrapulmonary pressure such that the opening of the glottis evokes a rapid expiratory airflow (expulsive phase). Expiration reflex is a variation of cough triggered by mechanical probing of the glottis, laryngeal vocal folds, and tracheal mucosa without an initial inspiratory effort. While objects detected in the glottis or larynx are removed by the expiratory reflex, those in the deeper parts of the airways may require an inspiratory effort to generate a high airflow velocity for removal by coughing (Mazzone \& Undem, 2016)

Acute and subacute coughs ( $<8$ weeks of duration) (Irwin, French, Chang, Altman \& Panel*, 2018) are usually resulted from upper respiratory tract infections caused by viruses or bacteria. These coughs are often resolved once the infection is cleared from the airways. However, chronic cough, also known as cough hypersensitivity syndrome, is a condition with a long-standing hypersensitivity or dysregulation of the vagal nervous system (Chung, 2011; Morice, Faruqi, Wright, Thompson \& Bland, 2011). The four most common background disorders for chronic coughs are asthma, eosinophilic bronchitis, chronic rhinosinusitis and oesophageal reflux disease (Chung \& Pavord, 2008). Some patients cough excessively due to airway nerve hypersensitivity, without any known pathological complications (Buday, Kovacikova, Ruzinak \& Plevkova, 2017). Cough in chronic respiratory tract diseases is an unpleasant experience and may represent an exaggerated reflex.

Pharmaceutical products are formulated as inhalation aerosols for faster onset of action in the treatment of respiratory diseases. Inhaled therapeutic agents can be delivered as liquid or dry powder aerosols using one of the three delivery platforms: nebulisers, pressurised metered-dose inhalers (pMDIs) and dry powder inhalers (DPIs). Over the years, there has been clinical reports of cough induced by inhaled pharmaceutical aerosols. This article aims to systemically review the literature on clinical studies of inhaled therapeutics to unravel the cause of cough stimulation. This would provide insight on how cough-associated adverse events may be minimised. An understanding of the cough physiology and different types of airways stimulant are necessary before investigating the impact of inhalation products on evoking cough.

\section{Cough, airway sensory nerves and cough receptors}

Cough receptors are located in the very peripheral ends of axons of neurons involved in the sensory innervation of the airways that rise towards the central nervous system in the vagus nerve. The nuclei of these nerves are in the jugular or nodose ganglia. If the receptors are activated with sufficient intensity, an action potential would then be generated and travel through the vagus nerve and synapses in the medulla where the cough reflex is processed (Bonvini \& Belvisi, 2017). The cough reflex arc (Figure 1) constitutes the afferent, central, and efferent pathways. The afferent impulses go to the medulla, which coordinates the autonomic functions 
of breathing. The central pathway, which coordinates coughing, is situated in the upper brain stem and pons. The efferent pathway sends signals from the cough centre to the muscles, abdominal wall, and diaphragm via the phrenic, vagus, and spinal motor nerves (Bonvini \& Belvisi, 2017). The central nervous system (CNS) interprets signals from the vagal afferent nerves and elicit changes in the breathing rate and depth and autonomic flow to airway smooth muscles. However, urge of coughing and feeling of dyspnoea may result if certain afferent nerves in the airways are activated. If the sensory nervous system becomes dysregulated in illnesses (e. g. rhinitis, bronchitis, asthma, and COPD), it may cause bronchospasm, urge of coughing, and dyspnoea (Mazzone \& Undem, 2016).

The airway afferent nerve system is generally classified by the fibre conduction velocities. C-fibres are the slowest in conducting signals and then followed by B-fibres, which are autonomous (Table 1). A-fibres are the fastest, which are further classified as $A \delta, A \gamma$ and $A \beta$, from the slowest to the fastest in conduction. However, since $\mathrm{A} \gamma$ fibres are efferent autonomic nerves, the ranking of vagal sensory nerves in the order of increasing conduction velocity are $\mathrm{C}-, \mathrm{A} \delta$, and $\mathrm{A} \beta$ fibres. C-fibres respond to potentially damaging mechanical forces, as well as inflammatory mediators and acidic chemicals (Mazzone \& Undem, 2016). There are two types of C-fibres, namely, pulmonary and bronchial. Pulmonary C-fibres respond to chemical stimulants with short latency when delivered through the right atrial injection into the pulmonary circulation. On the other hand, bronchial C-fibres are in the large airways and respond to chemical stimulants with short latency injected directly into the systemic circulation. A-fibres generally respond to mechanical forces with low thresholds. A $\delta$ fibres lead to cough and serve almost exclusively the larynx, trachea, and bronchi. They do not respond to tissue distention, airway smooth muscle contraction, and inflammatory mediators. However, they are sensitive to mechanical stimulation of, and sudden acidity in, the epithelium. If the $\mathrm{pH}$ decreases gradually, the acid-sensing mechanism adapts to it before signal conductance occurs (Mazzone \& Undem, 2016). A $\beta$ fibres respond to the lung distention and deflation during breathing. The mechano-sensitive $\mathrm{A} \beta$ fibres are subcategorised as rapidly-adapting receptors (RARs) and slowly-adapting receptors (SARs). RARs are activated by lung deflation, bronchospasm, and changes in dynamic lung compliance. SARs' action potential conduction velocities are faster than RARs and have a different distribution in the airways. SARs also respond to the mechanical forces that occur during tidal breathing (Figure 2 and Table 1) (Mazzone \& Undem, 2016).

Transient receptor potential (TRP) channels are a group of ion channels consisting of 28 members that are expressed by many types of cells. TRP-vanilloid-1 (TRPV1), TRP-ankyrin-1 (TRPA1), and TRP-melastatin8 (TRPM8) are the most important TRP channels related to cough. Capsaicin strongly activates most vagal C-fibres through the TRPV1 receptors, which are sensitive to acid and heat too. TRPA1 is expressed in Cfibre afferent neurons and colocalised with TRPV1. Therefore, inhalation of TRPV1 or TRPA1 agonists will cause coughing. TRPA1 can be activated by natural molecules (e.g. allyl isothiocyanate, allicin, cannabinol) and environmental irritants (e.g. acrolein, hypochlorite, hydrogen peroxide). TRPM8 is a receptor for menthol and cold temperatures but it constitutes only about $15 \%$ of bronchopulmonary C-fibres (Bonvini \& Belvisi, 2017; Mazzone \& Undem, 2016).

Inhalation of acidic aerosols leads to coughing in human and laboratory animals because they can activate all C-fibres in the airways through TRPV1 receptors. A-fibres can also be activated by acidic stimuli. Acidsensing ion channels (ASIC) also contribute to acid-induced action potential discharge. Other endogenous compounds that can stimulate action potential discharge are bradykinin, histamine (secondary to ATP release), serotonin, adenosine, and prostaglandins (PG) so inhalation of $\mathrm{PGD}_{2}$, and $\mathrm{PGF}_{2 \alpha}$ can cause cough (Mazzone \& Undem, 2016).

Considering patients that inhale therapeutic aerosols, it is understood that the stimulus threshold for coughing is significantly lower in patients with pulmonary diseases (Wong \& Morice, 1999). Further those with chronic cough have a continuous urge to cough. These conditions indicate that the affected airways have higher basal vagal afferent activity and sensory hypersensitivity. Autacoids (e.g. chemokines, cytokines, purines, eicosanoids) and ATP present in inflammatory airway diseases can stimulate the C-fibres in the respiratory tract to induce coughing. ATP receptor antagonists can decrease coughing frequency through 
inhibiting the stimulation of airway nodose C-fibres by ATP (Mazzone \& Undem, 2016). For example, AF219 works by blocking ATP receptors P2X3 and P2X2,3 thereby reducing frequency of coughs in a phase 2 clinical trial (Abdulqawi et al., 2015). Touch-sensitive airway mechanosensitive afferent receptors respond vigorously to light punctate mechanical stimuli. These cough receptors are located on many nodose-derived A-fibres in large airways (e.g., larynx, trachea, and main bronchi) (Bonvini \& Belvisi, 2017).

Airway inflammation increases the release of various neurotrophic factors that can interact with receptors at the nerve terminals and leads to gene expression changes in the distal vagal ganglia. For example, allergic inflammation may cause phenotypic changes in SAR and PAR neurons to express TRPV1 ion channels, which are normally absent. These nerves consequently become sensitive to capsaicin and other endogenous TRPV1activating stimuli. Airway inflammation may also upregulate the functional TRPV1 channels in tracheal A $\delta$ neurons that normally do not express these them. Nodose C-fibre neurons may develop responsiveness to neurokinins under similar circumstances. Due to these phenotypic changes, stimuli that are normally inert may potentially cause coughing, bronchospasm, and dyspnoea. Large-diameter RAR/SAR neurons as well as tracheal Aס neurons start to express neuropeptides, such as substance P, and express and transport peptides such as calcitonin gene-related peptide (CGRP) and neurokinins

(Mazzone \& Undem, 2016). Peripheral tissue inflammation or neuropathic injury may increase excessive neuronal activity in the central nerves that result in central sensitisation (Mazzone \& Undem, 2016).

\section{Disease status and cough to inhaled agents}

The cough patterns induced by aerosol products in healthy and diseased people are different. For example, nebulised antibiotics cause more severe coughing and wheezing in non-cystic fibrosis bronchiectasis patients compared to cystic fibrosis patients (Cipolla \& Chan, 2013). Patients are pre-treated with bronchodilators to reduce the frequency and severity of these adverse events (Elkins et al., 2006). Drug deposition profile may be affected by the extent of bronchoconstriction, changes in bronchial blood flow, or the presence of excess mucus or oedema. The consequences of reduced airway calibre lead to increased drug deposition in the larger central airways, provoke cough, and lead to insufficient delivery of drug to the target site (Richards, Haas, Simpson, Britten, Renwick \& Holgate, 1988; Satia, Badri, Al-Sheklly, Smith \& Woodcock, 2016).

Asthma is one of the most common causes of chronic cough in non-smoking adults (Morice, 2004). Moreover, cough as a symptom is more common in patients with severe asthma. Moderate-to-severe asthmatic patients suffer from persistent cough and mucus hypersecretion (de Marco et al., 2006). Cough impacts the quality of life of some asthmatic patients and is a major contributor to poor asthma control (Purokivi, Koskela \& Kontra, 2013). The incident rate of cough is significantly higher in asthmatic patients than in healthy subjects (Bonvini \& Belvisi, 2017). Cough sensitivity to capsaicin and citrate does not increase in asthma, whereas cough in response to hypertonicity is more pronounced in asthmatic patients (Koskela, Purokivi, Kontra, Taivainen \& Tukiainen, 2008). Bronchoconstriction mediators such as methacholine, substantial loss of respiratory heat and water during exercise, and increased ATP levels associated with inflammation may induce cough dyspnoea in asthmatic patients.

Similarly, COPD patients cough due to TRPV1 receptor activation or substantial airway inflammation and subsequent release of inflammatory mediators (e.g., tussive agents such as tachykinins, cough reflex stimulants such as prostaglandins) (Choudry, Fuller \& Pride, 1989; Joos, De Swert, Schelfhout \& Pauwels, 2003). Anti-cholinergic tiotropium used as bronchodilator activity in patients with asthma can help relieve symptoms and attenuates cough (Birrell et al., 2014). Acrolein and crotonaldehyde in cigarette smoke can also induce cough through stimulating TRPA1 receptors. This suggests a potential role for TRPA1 receptors in coughs induced by cigarette smoke, which is closely linked to COPD development (Mazzone \& Undem, 2016). Furthermore, COPD coughs may be induced by increased protease levels stimulating TRPV4 and TRPA1 receptors (Grace et al., 2014), as well as through mechanical stimulation by the excess mucus in the airways (Hogg, 2004). 
The frequency of cough in idiopathic pulmonary fibrosis (IPF) is even higher than in asthma or COPD, even though it is a marker of poor prognosis (Ryerson, Abbritti, Ley, Elicker, Jones \& Collard, 2011). TRPV1 and ATP (P2X3) receptors may be involved in the generation of cough in IPF patients. Oral inhalation of sodium cromoglicate can reduce the cough frequency of IPF patients by $31 \%$ (Birring et al., 2017). Inflammation and mechanical distortion of the lungs may affect nerve fibres and increase cough reflex sensitivity to mechanical stimulation of the chest wall (Bonvini \& Belvisi, 2017).

Increased cough response is also observed in patients with viral respiratory infections (Empey, Laitinen, Jacobs, Gold \& Nadel, 1976). Viral infection exposes the sensory nerves by damaging the airway epithelial cells, rendering them to higher responsiveness to mechanical and chemical stimuli (Empey, Laitinen, Jacobs, Gold \& Nadel, 1976). Cough may also be induced by the production of inflammation-associated mediators that sensitise sensory nerve endings (Fuller \& Jackson, 1990). Depending on the respiratory disease status of the patient, cough can be induced by mechanical or chemical stimulation of various ion channels, which activates sensory nerves and the cough reflex. Understanding of the cough pathophysiology has the potential to design drugs that target the receptors of interest and provide quality of life to chronic lung disease patients.

\section{Cough challenge tests}

Cough challenge relies on the delivery of tussive agents as aerosols from an inhalation device and the subsequent recording of the number of induced coughs. The agents can be administered as liquid droplets using jet or ultrasonic nebulisers (through a mouthpiece or facemask) or powders using breath-actuated dry powder inhalers. Nebulisers are often used with a dosimeter to control the inspiratory flow rate, as it can affect the cough response. The dosimeter generates a burst of compressed air that initiates a fixed duration of nebulization. In each challenge, the agent is delivered in increasing concentrations. The concentration that induces at least two coughs per inhalation is reported. Commonly used tussive agents include capsaicin, citric acid and mannitol.

Capsaicin has been used extensively for cough challenge as it induces cough in a dose-dependent and reproducible manner (Midgren, Hansson, Karlsson, Simonsson \& Persson, 1992). Capsicin dissolved in alcohol is serially diluted in isotonic saline to prepare different concentrations between $0.15-305 \mu \mathrm{g} / \mathrm{mL}$. Nebulised capsaicin aerosol is thought to induce cough through activating C-fibres via TRPV1 in the airways (Fuller, Dixon \& Barnes, 1985). Furthermore, oral administration of capsaicin can also desensitise the cough reflex by acting on TRPV1 receptors in the gastrointestinal system, known as central reflex desensitisation (Ternesten-Hasseus, Johansson \& Millqvist, 2015). Citric acid is another commonly used tussive agent that induces cough through the C-fibres. In addition, nebulised citric acid aerosols have been reported to stimulate RARs within the larynx and the upper airways (Morice, Kastelik \& Thompson, 2001). The traditional cough provocation tests using capsaicin or citric acid usually show a wide normal range of responses. The cough sensitivity achieved by this method poorly correlated with the symptoms (Buday, Kovacikova, Ruzinak \& Plevkova, 2017).

Mannitol challenge test is a regulatory approved bronchial provocation test that uses dry powder mannitol with a handheld dry powder inhaler. Similar to hypertonic saline, mannitol provides an osmotic stimulus to airways and provokes cough. The subject inhales mannitol powders with increasing doses of $0,5,10$, $20,40,80,160,160$, and $160 \mathrm{mg}$, with a maximum cumulative dose of $635 \mathrm{mg}$. Inhaled mannitol was initially developed as a bronchial hyper-responsiveness test for asthma diagnosis (Koskela, Lake, Wong \& Brannan, 2018), and then later found its utility as a cough challenge test. A recent study by Kanth et al. demonstrated that cough induced by nebulised mannitol $(40 \mathrm{mg} / \mathrm{mL}, 220 \mathrm{mOsm} / \mathrm{L})$ is dependent on the particle size distribution (Kanth, Alaienia \& Smaldone, 2018). No subjects coughed when inhaling $1.2 \mu \mathrm{m}$ mannitol aerosols, while $6.5 \mu \mathrm{m}$ particles caused coughs in $86 \%$ of the subjects.

Both liquid and dry powder aerosols containing tussive agents can induce cough. Patients as well as healthy subjects experience coughs upon inhalation, though the severity and number of induced coughs may vary. 
The likelihood of inducing coughs increases with higher delivered doses of tussive agents. Furthermore, the dose required to induce coughs depends on the compound. For example, capsaicin is used in the microgram range whereas milligrams of mannitol is used for cough challenge tests.

\section{Factors in inhalational products contributing to cough}

Advance in particle engineering techniques and novel device designs have widened the variety of inhalation formulations (Zhou, Leung, Tang, Parumasivam, Loh \& Chan, 2015). Inhalation products are often designed and engineered to minimise systemic side effects or to avoid first-pass metabolism. On the other hand, large molecules, such as insulin, are inhaled to allow deep lung deposition for systemic delivery. Orally inhaled drugs can deposit in the extra-thoracic region (mouth, oropharynx, and larynx), the central airways, and peripheral lung. Even with highly efficient inhalation delivery platforms, some of the dose may still deposit in the extra-thoracic region and be swallowed. Particle deposition in the deep lung could be enhanced using particles with a small aerodynamic diameter of $0.1-2 \mu \mathrm{m}$ coupled with a low inspiratory flow $(<20 \mathrm{~L} / \mathrm{min})$. Smaller particles $(<0.1 \mu \mathrm{m})$ will result in low deposition due to high amounts of them being exhaled. Larger particles will likely deposit in the upper and large airways where the majority of cough and expiration reflex receptors are located (Mazzone \& Undem, 2016). Therefore, to avoid coughs, it would be beneficial to design the aerosol delivery so that the particles preferentially deposit in the small airways.

\subsection{Dose of inhalation products}

In most cases, increasing the dose of inhaled drug can increase the chance of cough. It may be due to the increased concentration of the drug at the cough receptors. In a Phase I study on inhaled capreomycin powder, capsules loaded with a spray dried powder consisting of $25 \mathrm{mg}$ capreomycin and $5 \mathrm{mg}$ of L-leucine were used with a Cyclohaler. Drug doses of $25 \mathrm{mg}, 75 \mathrm{mg}, 150 \mathrm{mg}$, and $300 \mathrm{mg}$ were investigated, which corresponded to inhaling from $1,3,6$, and 12 capsules. Coughing occurred in five of the 20 healthy subjects across all doses. The coughs ranged from mild (for $25 \mathrm{mg}$ and $75 \mathrm{mg}$ ) to moderate (for $150 \mathrm{mg}$ and 300 $\mathrm{mg}$ ) and subsided within five minutes after inhaling powder from the last capsule. (Dharmadhikari, Kabadi, Gerety, Hickey, Fourie \& Nardell, 2013). It may be argued from this study that the severity of the cough increased, albeit slightly, with the inhaled drug dose. However, another phase I clinical study showed a lack of relationship between increases in the dose and reports of cough (Jansat, Lamarca, de Miquel, Schrodter, Miletzki \& Gurniak, 2009). Only two cases of cough were reported in 16 healthy volunteers who received 200, 400, and $800 \mu \mathrm{g}$ of aclidinium or placebo. This phenomenon can be explained by the fact that longacting muscarinic receptor antagonists (LAMAs), including aclidinium and tiotropium, can downregulate the cough reflex. These two LAMAs have antitussive effects in anaesthetised rabbits in response to citric acid challenge. These effects may be related to the downregulation of TRPV1, ASIC, and mechanoreceptors of cough-related airway sensory afferent neurons (Mutolo, Cinelli, Iovino, Pantaleo \& Bongianni, 2016).

Poorly dispersed powders that deposit in large airways are more likely to initiate a cough response through the touch-sensitive mechanosensitive nerves. Furthermore, the occurrence of coughing may be related to the amount of powder inhaled per bolus and its subsequent osmotic effect, which is dependent on the extent of dispersion and deposition (Velkov, Abdul Rahim, Zhou, Chan \& Li, 2015). Minimizing the use of excipients in the aerosol formulation may reduce the chance of coughing. Budesonide formulation without any excipients as a dry powder (lower powder dose) caused less cough than when using a metered dose inhaler (MDI) that contained propellants and lubricants (Engel, Heinig, Malling, Scharling, Nikander \& Madsen, 1989). However, different deposition in the airways from these two products could be a confounding factor to the difference in cough. Although cough is generally associated with the inhaled dose, the same dose of tobramycin inhalation solution (TIS) delivered using the same nebuliser showed different cough profiles, probably due to patients' former exposure (hence acclimatized) to inhaled aerosols (Konstan et al., 2011). However, individual variation in the upper airway anatomical features and deposition in the large airways may also contribute to the difference observed. 


\subsection{Dry vs wet aerosols}

Direct comparison of powder and liquid aerosols in cough production is difficult as device- or patient-related factors may also be involved. The EAGER trial assessed the safety of tobramycin inhalation powder (TIP ${ }^{\mathrm{TM}}$ ) and solution (TIS, TOBIR) (Konstan et al., 2011). TIP (112 mg) and TIS (300 mg/5 mL) were delivered using a Novartis T-326 Inhaler and a PARI LC PLUS ${ }^{\circledR}$ nebuliser, respectively. Cough was frequently reported for both forms of aerosol ( $48 \%$ and $31 \%$ for TIP and TIS, respectively). The higher cough incidents in TIPtreated patients across all age groups (Geller, Nasr, Piggott, He, Angyalosi \& Higgins, 2014) may be due to the faster administration, i.e. more airway receptors were activated within a shorter timeframe. Furthermore, the open-label design of this study as well as prior TIS-use in some patients may have had an impact on the tendency to report cough as an adverse event. Nonetheless, cough severity was mostly mild and moderate, with $<4 \%$ and $1 \%$ of TIP and TIS-treated patients discontinuing the treatment due to coughing, respectively. In another study, mild and self-limited coughs were observed in $20 \%$ of TIP subjects and none in TIS (Geller, Konstan, Smith, Noonberg \& Conrad, 2007). TIS subjects (85\%) were previously exposed to this treatment as part of their usual therapy so it is difficult to directly compare the two types of aerosol formulations. Furthermore, 92\% of TIP subjects reported coughing prior to TIP administration, which implies that this adverse event might be disease- or patient-related. Other studies have also reported coughing as a common adverse event after TIS treatment in cystic fibrosis (CF) (Greenwood et al., 2017; Hubert et al., 2009; Lenney, Edenborough, Kho \& Kovarik, 2011; Mazurek et al., 2014) and bronchiectasis (Barker et al., 2000; Scheinberg \& Shore, 2005) patients. Nebulised colistimethate sodium also caused coughing in a small proportion of CF subjects (Greenwood et al., 2017). Although TIP induced coughs, the post-inhalation cough rates reduced over time with repeated dosing, probably due to acclimatization of the airways and cough receptors.

Nebulised colistin sulphometate in normal saline $(160 \mathrm{mg})$ did not cause coughing in healthy subjects (Le Brun et al., 2002a).. However, moderate-to-severe coughs were induced by colistin sulfate powder (25 mg) (Le Brun et al., 2002a) and high incidence of cough with colistimethate sodium powder (125 mg) (Schuster, Haliburn, Doring \& Goldman, 2013) in CF subjects after inhalation of the powders. The varied cough profiles could be due multiple factors, including differences in molecular forms of colistin, aerosol performance (inhaler and formulation) and deposition in the respiratory tract. Nebulised colistin sulphomethate produced no cough and was better tolerated than colistin sulfate, which induced throat irritation and severe coughing (Le Brun et al., 2002a; Westerman et al., 2007; Westerman, Le Brun, Touw, Frijlink \& Heijerman, 2004). However, it is still not possible to pinpoint whether the difference observed is solely due to the chemical nature of the drugs and/or differences in the solution properties $(\mathrm{pH} \sim 7.4$ and 5, osmolality 366 and $306 \mathrm{mOsm} / \mathrm{kg}$, for the colistin sulphomethate and colistin sulphate solutions, respectively)(Westerman, Le Brun, Touw, Frijlink \& Heijerman, 2004).

As mentioned previously, $\mathrm{A} \delta$ and $\mathrm{C}$ fibres are sensitive to changes in $\mathrm{pH}$ and osmolarity. Inhaled solid particles, if they are soluble, may increase the osmolality in the airways more than droplets as the latter have higher water content. Moreover, the $\mathrm{pH}$ and osmolarity of a liquid formulation can be easily controlled, thus minimising the potential to induce coughs.

A major difference between inhaled powder and liquid formulations is that the dispersion and deposition of solid particles are affected by the patient's inhalation profile. The T-326 Inhaler used for delivering TIP is a low-resistance inhaler, so high inspiratory flows can be achieved easily. This may result in the impaction of particles in the oropharynx and central airways, consequently causing cough (an expiratory reflex); though expiratory reflex can be present in the tracheobronchial tree (Widdicombe, 1995). The optimal inhalation profile for aerosol generation is formulation-dependent for a given inhaler. TIP particles are porous and dispersible with a small aerodynamic diameter. They only require slow and deep inhalation for effective dispersion. For other dry powder formulations, a high inspiratory flow rate may be needed to generate a sufficiently large fraction of fine particles to reach the peripheral airways. Particle deposition in the lungs of healthy subjects for TIP delivered using the T-326 Inhaler was three time higher than that for TIS with the PARI LC PLUS ${ }^{\circledR}$ nebuliser (Challoner et al., 2001; Newhouse et al., 2003). Therefore, the distribution of drugs in the lungs achieved by inhaled solid and liquid aerosols may be different due to aerosol output, 
size distribution and inter-patient differences in the inhalation profiles. This may explain varying reports in cough-related adverse events between studies.

\subsection{Salt form vs free base of drugs}

Most of the studies on inhaled tobramycin mentioned above used the sulfate salt. Interestingly, inhaled tobramycin free base showed a low incidence of cough. Only two out of eight subjects coughed during one of the four visits (Hoppentocht et al., 2016). This may be due to the lower oropharyngeal deposition from the relatively low flow rate $(34 \mathrm{~L} / \mathrm{min})$ produced through the Cyclops inhaler and/or the lower powder dose required with the free base of the drug compared to that with its sulfate form. This effect of different salt forms of a drug on coughing was also apparent when $25 \mathrm{mg}$ colistin sulfate from a DPI was less tolerable than $160 \mathrm{mg}$ nebulised colistin sulphomethate, with the former inducing moderate-to-severe cough (Le Brun et al., 2002a). However, the observed trend was confounded by the different types of inhaler (DPI vs nebuliser), formulation (solid vs liquid), and inhalation pattern. There are no studies so far that study the effect of the physical form of a drug on cough alone, with all other variables controlled.

\subsection{Particle size}

The level of throat irritation and cough depend on the aerodynamic particle size. Fine and ultrafine particles depositing in the alveoli, where there are no cough receptors, will not cause coughing. On the other hand, coarse particles $(>5 \mu \mathrm{m})$ inhaled at high inspiratory flow rates primarily deposit in the extrathoracic region where they can induce cough by stimulating cough and expiratory reflex receptors (Zwozdziaka, Gini \& Samek, 2017). Small particles in inhaled formulations $<5 \mu \mathrm{m}$ can minimize upper airway deposition and reduce the risk of coughing. However, the availability of fine particles in an aerosol depends on the dispersibility of the powder formulation, inhalation flow and anatomical features of the airway of the patient. These will become confounding factors in consideration of particle deposition and cough.

\subsection{Inhaler devices}

DPIs, pMDIs, and nebulisers are the three major devices for respiratory drug delivery. DPIs and pMDIs are small, portable devices for general use, whereas nebulisers are typically used in emergency care or at home for children and infants to deliver high doses of drugs (Backman, Adelmann, Petersson \& Jones, 2014). Nebulisers were found to induce less coughing than pMDIs or DPIs in patients with chronic cough for the administration of corticosteroids (Kamimura et al., 2012).

The type of inhalation device and the required mode of inhalation affect the drug delivery into the lungs. Some DPIs need high inhalation flow rates for dispersion and deagglomeration. Consequently, the particles may deposit in the upper airways due to inertial impaction and induce cough. Two breath-actuated DPIs, Turbohaler ${ }^{\circledR}(500 \mu \mathrm{g}$ terbutaline $)$ and Diskhaler ${ }^{\circledR}(400 \mu \mathrm{g}$ salbutamol) were compared in chronic asthma patients (Brown, Lenney, Armstrong, Ning \& Crompton, 1992). Despite differences in the drug, dose, and device design, both products showed very similar rates of cough and therapeutic effects (Table 2).

pMDIs generate aerosols that travel rapidly and require coordination between actuation and inhalation. The impaction problem can be addressed for pMDIs by using a spacer, which is essentially a chamber into which the dose is aerosolised, from which the patient inhales by breathing tidally. The spacer allows the propellant to evaporate to form smaller particles and decelerates the aerosol cloud, thereby reducing upper airway deposition. Despite this, spacers cannot eliminate coughing completely.

Dubus et al (2003) studied the local side effects in asthmatic children treated with fluticasone propionate, budesonide, or beclomethasone dipropionate delivered from pMDIs with small or large volume spacers (Dubus, Mely, Huiart, Marguet, Le Roux \& Reseau de Recherche Clinique en Pneumologie, 2003). About $54 \%$ of the patients coughed after inhaling each corticosteroid, with $30 \%$ of them also coughed after inhaling $\beta_{2}$-agonists. All three corticosteroids showed similar tendency of inducing cough, despite the pMDIs 
containing different propellants. This suggests that the induced cough was more likely to be dependent on the delivery device rather than the formulation. Coughing was not found to be associated with the severity of asthma but was related to the use of long-acting $\beta 2$-agonist (LABA) and duration of treatment. The type/volume of the spacer and the use of mouthpiece/facemask were deemed to not affect coughing (Table 2).

A study compared the efficacy and safety of inhaled budesonide ( 800 or $1600 \mu \mathrm{g}$ ) administered via a pMDI coupled to a $750 \mathrm{~mL}$ spacer and via a Turbohaler ${ }^{\circledR}$ in patients with stable asthma. The Turbohaler ${ }^{\circledR}$ showed significantly less coughs 5 minutes after inhalation than the pMDI with spacer (Engel, Heinig, Malling, Scharling, Nikander \& Madsen, 1989). This might be due to the absence of excipients in the Turbohaler ${ }^{\circledR}$ product as the powder only contained budesonide (Table 2). Other confounding factors such as the regional deposition in the airways and the dose deposited could also contribute to the difference in the cough.

Incorrect use of the device and/or inhalation technique may also be associated with chronic cough and wheezing (Lavorini et al., 2008). Before studying the rate of cough, the participants in the study must be sufficiently trained in using the device correctly and inhaling properly. Deep inspiration of corticosteroids from pMDIs in patients complaining of coughing induced large, but transient, specific airway resistance and bronchoconstriction (Dubus, Mely, Huiart, Marguet, Le Roux \& Reseau de Recherche Clinique en Pneumologie, 2003). Although deep inspiration may stimulate SAR and RAR receptors that normally does not evoke cough, these stretch fibres may change their phenotype and express RTPV1 receptors due to airway inflammation. The bronchoconstriction may be caused by pulmonary mechanoreceptor activation secondary to the release of ATP as discussed above (Mazzone \& Undem, 2016).

\subsection{Active ingredients}

Drugs may cause coughs by various mechanisms, such as stimulating cough receptors by changing the local acidity, osmolarity, and/or ATP release. They may also downregulate the cough response. Some drugs provoke more coughs than others, which highlights the importance of thorough clinical safety assessment.

\subsubsection{Corticosteroids}

Corticosteroids are important in the treatment of asthma and COPD owing to their anti-inflammatory effects. However, their role in the alleviation of chronic coughs has not been confirmed (Johnstone, Chang, Fong, Bowman \& Yang, 2013). A clinical study showed that budesonide and beclomethasone pMDIs showed equal tendency in causing coughs in $34 \%$ of the asthmatic patients (Williamson, Matusiewicz, Brown, Greening \& Crompton, 1995). High prevalence of coughs (53.7\%) was observed in asthmatic children receiving inhaled beclomethasone dipropionate, budesonide, or fluticasone propionate (Dubus, Mely, Huiart, Marguet, Le Roux \& Reseau de Recherche Clinique en Pneumologie, 2003) and was closely associated with therapy duration and combination-therapy with LABA. Coughing was more common in patients using higher daily doses of inhaled corticosteroid (>1500 $\mu \mathrm{g} /$ day) from pMDIs, although the difference in prevalence compared to that at lower doses was not statistically significant (Williamson, Matusiewicz, Brown, Greening \& Crompton, 1995). Using the pMDIs with a spacer did not prevent coughs. The cause of coughing by the corticosteroid pMDIs is yet unknown. An early study noted that a beclomethasone pMDI caused coughs in asthma patients whereas a triamcinolone pMDI did not (Shim \& Williams, 1987b). However, besides their different drugs and doses, those two pMDIs contained different propellants and excipients so it was difficult to identify the reason/s for the different cough responses. It may or may not be due to the drug. Interplay between the various formulation and aerosolization parameters may also be possible.

\subsubsection{Doxorubicin}

Cough was the most frequent adverse event in a Phase I study of inhaled doxorubicin (Otterson et al., 2007). Increased cough was observed in $50 \%$ of the patients with metastatic tumours to the lung. The irritant 
nature of the drug and acidic alcoholic formulation at $\mathrm{pH} 3$ may contribute to the high rate of cough (Table 2).

\subsubsection{Antibiotics}

Inhaled antibiotics are commonly used for treating lung infections in patients with cystic fibrosis and bronchiectasis. Coughs after inhaling antibiotics have been reported as mild and transient (Barker et al., 2000; Conole \& Keating, 2014; Konstan, Geller, Minic, Brockhaus, Zhang \& Angyalosi, 2011). Although the incidence of cough was high after the administration of antibiotics, the coughs reduced after 28 days of treatment (Conole \& Keating, 2014). This might be due to an alleviation of the inflammation and infection in the lungs, which strongly provoke cough. Cough prevalence was reduced in the 28-day treatment $\mathrm{Cy}$ cles 4 to 6 (21-22\%) compared to Cycle 1 (31.4\%) in patients receiving inhaled tobramycin (Sommerwerck, Virella-Lowell, Angyalosi, Viegas, Cao \& Debonnett, 2016). In patients with cystic fibrosis, the rationale for the 28-day on/28-day off cycle of inhaled antibiotic administration depends on the peak increase in lung function after 28 days of continuous antibiotic administration. The 28-day off period reduces the likelihood of the emergence of antibiotic-resistant organisms (Table 2). In a study by Geller et al (2007), cough was only observed in patients receiving TIP (20\%) (Geller, Konstan, Smith, Noonberg \& Conrad, 2007). None in the TIS group coughed. As mentioned in Section 5.2, TIS patients had prior exposure to inhaled antibiotics treatment. Thus it is difficult to conclude that the reduced cough incidence was associated with the improvement in patients' symptoms because it could be due to adaptation to the therapy (Geller, Konstan, Smith, Noonberg \& Conrad, 2007). Tobramycin has anti-inflammatory effects beyond its antimicrobial activity (Gziut, MacGregor, Nevell, Mason, Laight \& Shute, 2013). Other antibiotics, such as macrolides, doxycycline, moxifloxacin, and polymyxin B, can also reduce inflammation in the lungs (Huckle, Fairclough \& Todd, 2018; Lin et al., 2017). Thus, besides treating the underlying infection, antibiotics may decrease the stimulation of C-fibres and consequent reduce cough by reducing inflammation in the airways. The fact that they can also provoke cough point to other molecular and/or formulation factors.

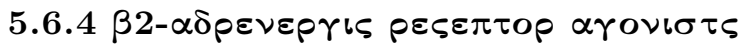

Indacaterol is formulated as a once-daily inhaled LABA for COPD treatment. A 12-week, double-blind study tested inhaled indacaterol (150 $\mu \mathrm{g}$ from a DPI) in patients with moderate-to-severe COPD (Feldman, Fakorede, Minutello, Bergman, Moussa \& Wong, 2010). The overall rates of cough in indacaterol-treated and placebo groups were comparable (Table 2). No association between coughing and bronchospasm was found. Inhalation of salbutamol and terbutaline from a DPI caused coughing in one third of patients with chronic asthma in another study (Table 2) (Brown, Lenney, Armstrong, Ning \& Crompton, 1992). Pre-treatment with inhaled salbutamol did not prevent saline hypertonicity-induced coughs in healthy volunteers (Koskela, Purokivi, Kontra, Taivainen \& Tukiainen, 2008).

$\beta 2$-adrenergic receptors ( $\beta 2$-ARs) have been proposed to be involved in the cough reflex. However, they have different effects in animal cough models. Dose-dependent inhibition of coughs was observed in naïve and ovalbumin-sensitised guinea pigs, whereas formoterol and salmeterol tended to reduce coughs (Wex \& Bouyssou, 2015). Interestingly, indacaterol demonstrated pro-tussive properties with increased coughing in both animal groups. Although these data cannot be translated directly to $\beta 2$-ARs in humans, it shows that drug molecules can have different effects on cough receptors.

\subsubsection{Antimuscarinic drugs}

Jansat et al assessed the tolerability of inhaled aclidinium bromide, a long-acting antimuscarinic drug (Jansat, Lamarca, de Miquel, Schrodter, Miletzki \& Gurniak, 2009). Healthy subjects received 200, 400, or $800 \mu \mathrm{g}$ of aclidinium bromide or placebo from a DPI for 5 days, with [?]7 days washout periods. The frequency of adverse events was comparable between the treated and placebo groups. Only two participants reported mild and probably treatment-related coughs. Aclidinium and tiotropium may downregulate the cough reflex 
and interact with TRPV1 receptors, acid-sensing ion channels, and mechanoreceptors in the airway nerves (Mutolo, Cinelli, Iovino, Pantaleo \& Bongianni, 2016).

\subsubsection{Insulin}

Despite successful efficacy of inhaled insulin, the rate of reported cough was high compared to conventional subcutaneous insulin in Type 2 diabetes patients and healthy volunteers (Table 2). One of the reasons for withdrawing inhaled insulin powder (Exubera ${ }^{\circledR}$ ) was the persistent reports of respiratory adverse effects, including cough. The high prevalence of cough may be related to the complex formulation containing sodium citrate, mannitol, glycine, sodium hydroxide, which are cough inducers. The rate of coughing was much less with Technosphere ${ }^{\circledR}$ insulin (TI) in Afrezza ${ }^{\circledR}$, another inhaled insulin DPI product. This powder contains fumaryl diketopiperazine as an excipient (Angelo, Rousseau, Grant, Leone-Bay \& Richardson, 2009). The rate of mild-to-moderate coughs after the administration of Exubera ${ }^{\circledR}$ was much higher than that for subcutaneous insulin injection (27\% vs 5\%, respectively) (Quattrin, Belanger, Bohannon, Schwartz \& Exubera Phase, 2004). On the other hand, TI showed similar cough incidents as the placebo powder $(23.7 \%$ vs 19.9 , respectively) (Rosenstock et al., 2015), suggesting that the coughs were due to the excipients rather than insulin. The coughs triggered by inhaled insulin, whether due to the excipients or insulin itself, are mild and will gradually subside with treatment (Ceglia, Lau \& Pittas, 2006). This could be due to acclimatization to the inhaled formulation. The coughs are not associated with changes in pulmonary function (Ceglia, Lau \& Pittas, 2006), despite the pathological association of diabetes with modest pulmonary function impairment (van den Borst, Gosker, Zeegers \& Schols, 2010).

\subsubsection{Mannitol}

Mannitol has been identified to trigger cough and used to identify subjects with chronic cough and diagnose asthma (see Section 4) (Koskela, Lake, Wong \& Brannan, 2018; Minasian, Wallis, Metcalfe \& Bush, 2008). Inhaled mannitol or other hyperosmolar agents can stimulate the release of bronchoconstricting mediators in the airways and provoke cough (Lowry, Wood \& Higenbottam, 1988). Mannitol also increases mucociliary clearance in the airways and assists mucus removal in cystic fibrosis patients. Mannitol decreases the viscosity of phlegm, hydrates the airway surface liquid, and increase mucociliary activity (Flume et al., 2015). The rate of cough caused by inhaled mannitol powder was much higher in asthmatic (85.3\%) (Brannan et al., 2005) compared to cystic fibrosis patients (25.4\%) (Bilton et al., 2011), despite the lower administered doses (Table 2).

\subsubsection{Treprostinil}

Treprostinil is a tricyclic benzindene prostacyclin analogue used for the treatment of pulmonary arterial hypertension (PAH) (McLaughlin et al., 2010). PAH patients suffer from reduced prostacyclin synthase activity, which leads to inadequate prostacyclin I2 production. The prostacyclin deficiency causes vascular proliferation, vasoconstriction, and platelet aggregation. Activation of prostacyclin receptors in the lung can reverse these effects (Kingman, Archer-Chicko, Bartlett, Beckmann, Hohsfield \& Lombardi, 2017). In a randomised clinical trial, inhaled treprostinil via an Optineb nebuliser in addition to oral therapy, $54 \%$ of patients coughed in contrast to the $29 \%$ in the placebo group (McLaughlin et al., 2010). Inhalation of treprostinil in dog and guinea pigs also caused coughing (Corboz et al., 2017). The pro-tussive effect may be attributed to the drug being acidic.

\subsection{Excipients}

Table 2 shows that coughing has been reported for placebo formulations in some clinical trials, including the study on treprostinil (McLaughlin et al., 2010) and tobramycin (Konstan, Geller, Minic, Brockhaus, Zhang \& Angyalosi, 2011). This indicates that excipients can also cause cough. Powder formulations containing engineered particles can contain complex excipients which trigger cough as described for insulin (Section 5.5.6). 
Oleic acid and fluorocarbon propellants from pMDIs can cause coughs in asthmatic patients (Shim \& Williams, 1987a; Shim \& Williams, 1987b). Aerosols containing the above excipients with and without beclomethasone caused coughs 31 and 19 times, respectively (Shim \& Williams, 1987a). Since the reduction in FEV1 was similar in both groups $(22 \%)$, the broncoconstriction was caused by the excipients rather than the drug. Inhaled triamcinolone acetonide was better tolerated than beclomethasone in another study(Shim \& Williams, 1987a). It was proposed that the excipients, particularly oleic acid, caused cough and bronchoconstriction. Sterling and Battern demonstrated that sorbitol triolates and lecithin can cause cough and bronchoconstriction in asthmatic patients (13 and $21 \%$ reduction in airway conductance, respectively) (Sterling \& Batten, 1969). In healthy subjects they decreased airway conductance by 5.3 and $9.7 \%$, respectively, but were unlikely to be clinically significant.

Some preservatives used in inhalation products in the past, including phenol, can cause airway irritation, coughing, and bronchoconstriction. Sodium bisulfite and ethylenediaminetetraacetic acid (EDTA) are still permitted in various pharmaceutical inhalation products to enhance chemical stability but they can both cause bronchoconstriction (Pilcer \& Amighi, 2010).

\section{Conclusion}

Despite great improvement in inhalation drug delivery systems, cough is still a limiting adverse effect affecting patients' compliance and treatment efficacy as it would reduce the delivered dose. Cough is an important symptom of many respiratory diseases so it may be difficult to distinguish it from the adverse effects caused by the inhalation product. The underlying disease that cause cough and bronchoconstriction may also affect particle deposition and inhalation effort by the patient. Airway acclimatisation and the individual's response to cough stimulants are also important factors. Since cough can be due to so many confounding factors via direct or indirect effect of the stimulants, one cannot simply make general statements such as powder aerosols being more likely to cause cough than nebulized formulations, or vice versa, even for the same drug molecule. Well-controlled clinical studies specifically designed to address cough would be necessary to identify the underlying cause for cough encountered in patients during aerosol treatment.

In the airways, chemicals may stimulate A $\delta$ or C fibres by changing the acidity, osmolarity, or by directly activating the receptors. The cough receptors in diseased lungs are highly sensitised and can be stimulated easier compared to those in healthy people. Large particles may stimulate the punctate-sensitive cough receptors in large airways and trigger the expiratory reflex. Controlling the particles size of the formulation to $<5 \mu \mathrm{m}$ is necessary for minimising cough so that the particles deposit in the deep lung, where cough receptors are absent. However, such an approach

would need to take into account the site of therapeutic action. Besides particle size, the form of the aerosol, the dose, solid state of the drug, type of excipients, concentration, and $\mathrm{pH}$ and tonicity of the formulation should be considered to avoid causing cough. Higher doses of drugs and/or excipients can increase the risk of cough if the inhaled compounds can activate the cough receptors. Air flow characteristics through the inhaler device must be optimised to achieve the maximum aerosol performance and minimum airway irritation due to unwanted particle

deposition. At the same time, the inhaler should be sufficiently simple for patients to operate correctly. Figure 3 summarises these factors in the design and use of inhalation products to avoid causing coughs.

\section{Figure legends}

Figure 1. The cough reflex arc.

Figure 2. Common stimulants of airway vagal neurons.

Figure 3. Factors that influence cough in pulmonary drug delivery. 


\section{References}

Abdulqawi R, Dockry R, Holt K, Layton G, McCarthy BG, Ford AP, et al. (2015). P2X3 receptor antagonist (AF-219) in refractory chronic cough: a randomised, double-blind, placebo-controlled phase 2 study. Lancet 385: 1198-1205.

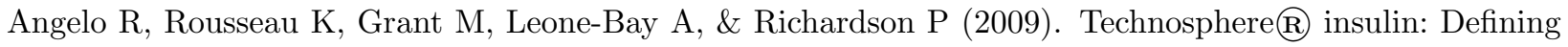
the role of Technosphere particles at the cellular level. J Diabetes Sci Technol 3: 545-554.

Backman P, Adelmann H, Petersson G, \& Jones CB (2014). Advances in inhaled technologies: understanding the therapeutic challenge, predicting clinical performance, and designing the optimal inhaled product. Clin Pharmacol Ther 95: 509-520.

Barker AF, Couch L, Fiel SB, Gotfried MH, Ilowite J, Meyer KC, et al. (2000). Tobramycin solution for inhalation reduces sputum Pseudomonas aeruginosa density in bronchiectasis. Am J Respir Crit Care Med 162: 481-485.

Bilton D, Robinson P, Cooper P, Gallagher CG, Kolbe J, Fox H, et al. (2011). Inhaled dry powder mannitol in cystic fibrosis: an efficacy and safety study. Eur Respir J 38: 1071-1080.

Birrell MA, Bonvini SJ, Dubuis E, Maher SA, Wortley MA, Grace MS, et al. (2014). Tiotropium modulates transient receptor potential V1 (TRPV1) in airway sensory nerves: A beneficial off-target effect? J Allergy Clin Immunol 133: 679-687.e679.

Birring SS, Wijsenbeek MS, Agrawal S, van den Berg JWK, Stone H, Maher TM, et al. (2017). A novel formulation of inhaled sodium cromoglicate (PA101) in idiopathic pulmonary fibrosis and chronic cough: a randomised, double-blind, proof-of-concept, phase 2 trial. Lancet Respir Med 5: 806-815.

Bonvini SJ, \& Belvisi MG (2017). Cough and airway disease: The role of ion channels. Pulm Pharmacol Ther 47: 21-28.

Brannan JD, Anderson SD, Perry CP, Freed-Martens R, Lassig AR, Charlton B, et al. (2005). The safety and efficacy of inhaled dry powder mannitol as a bronchial provocation test for airway hyperresponsiveness: a phase 3 comparison study with hypertonic (4.5\%) saline. Respir Res 6: 144.

Brown PH, Lenney J, Armstrong S, Ning AC, \& Crompton GK (1992). Breath-actuated inhalers in chronic asthma: comparison of Diskhaler and Turbohaler for delivery of beta-agonists. Eur Respir J 5: 1143-1145.

Buday T, Kovacikova L, Ruzinak R, \& Plevkova J (2017). TRPV4 antagonist GSK2193874 does not modulate cough response to osmotic stimuli. Respir Physiol Neurobiol 236: 1-4.

National Ambulatory Medical Care Survey: 2010 Summary Tables [Online] Available from https://www.cdc.gov/nchs/data/ahcd/namcs_summary/2010_namcs_web_tables.pdf. [Accessed: 7 Nov 2018].

Ceglia L, Lau J, \& Pittas AG (2006). Meta-analysis: efficacy and safety of inhaled insulin therapy in adults with diabetes mellitus. Ann Intern Med 145: 665-675.

Challoner P, Flora M, Hirst P, Klimowicz M, Newman S, Schaeffler B, et al. Gamma scintigraphy lung deposition comparison of TOBI in the Pari LC Plus nebulizer and the Aerodose inhaler.

Choudry NB, Fuller RW, \& Pride NB (1989). Sensitivity of the human cough reflex: effect of inflammatory mediators prostaglandin E2, bradykinin, and histamine. Am Rev Respir Dis 140: 137-141.

Chung KF (2011). Chronic 'cough hypersensitivity syndrome': a more precise label for chronic cough. Pulm Pharmacol Ther 24: 267-271.

Chung KF, \& Pavord ID (2008). Prevalence, pathogenesis, and causes of chronic cough. Lancet 371: 13641374 .

Cipolla D, \& Chan HK (2013). Inhaled antibiotics to treat lung infection. Pharm Pat Anal 2: 647-663. 
Conole D, \& Keating GM (2014). Colistimethate sodium dry powder for inhalation: a review of its use in the treatment of chronic Pseudomonas aeruginosa infection in patients with cystic fibrosis. Drugs 74: 377-387.

Corboz MR, Li Z, Malinin V, Plaunt AJ, Konicek DM, Leifer FG, et al. (2017). Preclinical pharmacology and pharmacokinetics of inhaled hexadecyl-treprostinil (C16TR), a pulmonary vasodilator prodrug. J Pharmacol Exp Ther 363: 348-357.

de Marco R, Marcon A, Jarvis D, Accordini S, Almar E, Bugiani M, et al. (2006). Prognostic factors of asthma severity: a 9-year international prospective cohort study. J Allergy Clin Immunol 117: 1249-1256.

Dharmadhikari AS, Kabadi M, Gerety B, Hickey AJ, Fourie PB, \& Nardell E (2013). Phase I, single-dose, dose-escalating study of inhaled dry powder capreomycin: a new approach to therapy of drug-resistant tuberculosis. Antimicrob Agents Chemother 57: 2613-2619.

Dubus JC, Mely L, Huiart L, Marguet C, Le Roux P, \& Reseau de Recherche Clinique en Pneumologie P (2003). Cough after inhalation of corticosteroids delivered from spacer devices in children with asthma. Fundam Clin Pharmacol 17: 627-631.

Elkins MR, Robinson M, Rose BR, Harbour C, Moriarty CP, Marks GB, et al. (2006). A controlled trial of long-term inhaled hypertonic saline in patients with cystic fibrosis. N Engl J Med 354: 229-240.

Empey DW, Laitinen LA, Jacobs L, Gold WM, \& Nadel JA (1976). Mechanisms of bronchial hyperreactivity in normal subjects after upper respiratory tract infection. Am Rev Respir Dis 113: 131-139.

Engel T, Heinig JH, Malling HJ, Scharling B, Nikander K, \& Madsen F (1989). Clinical comparison of inhaled budesonide delivered either via pressurized metered dose inhaler or Turbuhaler. Allergy 44: 220-225.

Feldman DN, Fakorede F, Minutello RM, Bergman G, Moussa I, \& Wong SC (2010). Efficacy of high-dose clopidogrel treatment $(600 \mathrm{mg})$ less than two hours before percutaneous coronary intervention in patients with non-ST-segment elevation acute coronary syndromes. Am J Cardiol 105: 323-332.

Flume PA, Aitken ML, Bilton D, Agent P, Charlton B, Forster E, et al. (2015). Optimising inhaled mannitol for cystic fibrosis in an adult population. Breathe (Sheff) 11: 39-48.

Fuller RW, Dixon CM, \& Barnes PJ (1985). Bronchoconstrictor response to inhaled capsaicin in humans. J Appl Physiol (1985) 58: 1080-1084.

Fuller RW, \& Jackson DM (1990). Physiology and treatment of cough. Thorax 45: 425-430.

Geller DE, Konstan MW, Smith J, Noonberg SB, \& Conrad C (2007). Novel tobramycin inhalation powder in cystic fibrosis subjects: pharmacokinetics and safety. Pediatr Pulmonol 42: 307-313.

Geller DE, Nasr SZ, Piggott S, He E, Angyalosi G, \& Higgins M (2014). Tobramycin inhalation powder in cystic fibrosis patients: response by age group. Respir Care 59:388-398.

Grace MS, Lieu T, Darby B, Abogadie FC, Veldhuis N, Bunnett NW, et al. (2014). The tyrosine kinase inhibitor bafetinib inhibits PAR2-induced activation of TRPV4 channels in vitro and pain in vivo. Br J Pharmacol 171: 3881-3894.

Greenwood J, Schwarz C, Sommerwerck U, Nash EF, Tamm M, Cao W, et al. (2017). Ease of use of tobramycin inhalation powder compared with nebulized tobramycin and colistimethate sodium: a crossover study in cystic fibrosis patients with pulmonary Pseudomonas aeruginosa infection. Ther Adv Respir Dis 11: 249-260.

Gziut M, MacGregor HJ, Nevell T, Mason T, Laight D, \& Shute JK (2013). Anti-inflammatory effects of tobramycin and a copper-tobramycin complex with superoxide dismutase-like activity. Br J Pharmacol 168: $1165-1181$.

Hogg J (2004). Peripheral lung remodelling in asthma and chronic obstructive pulmonary disease. Eur Respir J 24: 893-894. 
Hoppentocht M, Akkerman OW, Hagedoorn P, Alffenaar JW, van der Werf TS, Kerstjens HA, et al. (2016). Tolerability and pharmacokinetic evaluation of inhaled dry powder tobramycin free base in non-cystic fibrosis bronchiectasis patients. PLoS One 11: e0149768.

Hubert D, Leroy S, Nove-Josserand R, Murris-Espin M, Mely L, Dominique S, et al. (2009). Pharmacokinetics and safety of tobramycin administered by the PARI eFlow rapid nebulizer in cystic fibrosis. J Cyst Fibros 8: 332-337.

Huckle AW, Fairclough LC, \& Todd I (2018). Prophylactic antibiotic use in COPD and the potential antiinflammatory activities of antibiotics. Respir Care 63:609-619.

Irwin RS, French CL, Chang AB, Altman KW, \& Panel* CEC (2018). Classification of cough as a symptom in adults and management algorithms: CHEST guideline and expert panel report. Chest 153: 196-209.

Jansat JM, Lamarca R, de Miquel G, Schrodter A, Miletzki B, \& Gurniak M (2009). Safety and pharmacokinetics of multiple doses of aclidinium bromide, a novel long-acting muscarinic antagonist for the treatment of chronic obstructive pulmonary disease, in healthy participants. J Clin Pharmacol 49: 1239-1246.

Johnstone KJ, Chang AB, Fong KM, Bowman RV, \& Yang IA (2013). Inhaled corticosteroids for subacute and chronic cough in adults. Cochrane Database Syst Rev: CD009305.

Joos GF, De Swert KO, Schelfhout V, \& Pauwels RA (2003). The role of neural inflammation in asthma and chronic obstructive pulmonary disease. Ann N Y Acad Sci 992:218-230.

Kamimura M, Izumi S, Hamamoto Y, Morita A, Toyota E, Kobayashi N, et al. (2012). Superiority of nebulized corticosteroids over dry powder inhalers in certain patients with cough variant asthma or coughpredominant asthma. Allergol Int 61: 411-417.

Kanth PM, Alaienia C, \& Smaldone GC (2018). Nebulized mannitol, particle distribution, and cough in idiopathic pulmonary fibrosis. Respir Care 63: 1407-1412.

Kingman M, Archer-Chicko C, Bartlett M, Beckmann J, Hohsfield R, \& Lombardi S (2017). Management of prostacyclin side effects in adult patients with pulmonary arterial hypertension. Pulm Circ 7: 598-608.

Konstan MW, Flume PA, Kappler M, Chiron R, Higgins M, Brockhaus F, et al. (2011). Safety, efficacy and convenience of tobramycin inhalation powder in cystic fibrosis patients: The EAGER trial. J Cyst Fibros 10: $54-61$.

Konstan MW, Geller DE, Minic P, Brockhaus F, Zhang J, \& Angyalosi G (2011). Tobramycin Inhalation Powder for P. aeruginosa Infection in Cystic Fibrosis: The EVOLVE Trial. Pediatr Pulmonol 46: 230-238.

Koskela HO, Lake C, Wong K, \& Brannan JD (2018). Cough sensitivity to mannitol inhalation challenge identifies subjects with chronic cough. Eur Respir J 51.

Koskela HO, Purokivi MK, Kontra KM, Taivainen AH, \& Tukiainen HO (2008). Hypertonic saline cough provocation test with salbutamol pre-treatment: evidence for sensorineural dysfunction in asthma. Clin Exp Allergy 38:1100-1107.

Lavorini F, Magnan A, Dubus JC, Voshaar T, Corbetta L, Broeders M, et al. (2008). Effect of incorrect use of dry powder inhalers on management of patients with asthma and COPD. Respir Med 102: 593-604.

Le Brun PP, de Boer AH, Mannes GP, de Fraiture DM, Brimicombe RW, Touw DJ, et al. (2002a). Dry powder inhalation of antibiotics in cystic fibrosis therapy: part 2. Inhalation of a novel colistin dry powder formulation: a feasibility study in healthy volunteers and patients. Eur J Pharm Biopharm 54:25-32.

Le Brun PPH, de Boer AH, Mannes GPM, de Fratture DMI, Brimicombe RW, Touw DJ, et al. (2002b). Dry powder inhalation of antibiotics in cystic fibrosis therapy: part 2: Inhalation of a novel colistin dry powder formulation: a feasibility study in healthy volunteers and patients. Eur J Pharm Biopharm 54: 25-32. 
Lenney W, Edenborough F, Kho P, \& Kovarik JM (2011). Lung deposition of inhaled tobramycin with eFlow rapid/LC Plus jet nebuliser in healthy and cystic fibrosis subjects. J Cyst Fibros 10: 9-14.

Lin YW, Zhou Q, Onufrak NJ, Wirth V, Chen K, Wang J, et al. (2017). Aerosolized polymyxin B for treatment of respiratory tract infections: determination of pharmacokinetic-pharmacodynamic indices for aerosolized polymyxin B against Pseudomonas aeruginosa in a mouse lung infection model. Antimicrob Agents Chemother 61.

Lowry RH, Wood AM, \& Higenbottam TW (1988). Effects of pH and osmolarity on aerosol-induced cough in normal volunteers. Clin Sci (Lond) 74: 373-376.

Mazurek H, Chiron R, Kucerova T, Geidel C, Bolbas K, Chuchalin A, et al. (2014). Long-term efficacy and safety of aerosolized tobramycin $300 \mathrm{mg} / 4 \mathrm{ml}$ in cystic fibrosis. Pediatr Pulmonol 49: 1076-1089.

Mazzone SB, \& Undem BJ (2016). Vagal afferent innervation of the airways in health and disease. Physiol Rev 96: 975-1024.

McLaughlin VV, Benza RL, Rubin LJ, Channick RN, Voswinckel R, Tapson VF, et al. (2010). Addition of inhaled treprostinil to oral therapy for pulmonary arterial hypertension: a randomized controlled clinical trial. J Am Coll Cardiol 55: 1915-1922.

Midgren B, Hansson L, Karlsson JA, Simonsson BG, \& Persson CG (1992). Capsaicin-induced cough in humans. Am Rev Respir Dis 146: 347-351.

Minasian C, Wallis C, Metcalfe C, \& Bush A (2008). Bronchial provocation testing with dry powder mannitol in children with cystic fibrosis. Pediatr Pulmonol 43: 1078-1084.

Morice AH (2004). The diagnosis and management of chronic cough. Eur Respir J 24: 481.

Morice AH, Faruqi S, Wright CE, Thompson R, \& Bland JM (2011). Cough hypersensitivity syndrome: a distinct clinical entity. Lung 189: 73-79.

Morice AH, Kastelik JA, \& Thompson R (2001). Cough challenge in the assessment of cough reflex. Br J Clin Pharmacol 52: 365-375.

Mutolo D, Cinelli E, Iovino L, Pantaleo T, \& Bongianni F (2016). Downregulation of the cough reflex by aclidinium and tiotropium in awake and anesthetized rabbits. Pulm Pharmacol Ther 38: 1-9.

Newhouse MT, Hirst PH, Duddu SP, Walter YH, Tarara TE, Clark AR, et al. (2003). Inhalation of a dry powder tobramycin PulmoSphere formulation in healthy volunteers. Chest 124: 360-366.

Otterson GA, Villalona-Calero MA, Sharma S, Kris MG, Imondi A, Gerber M, et al. (2007). Phase I study of inhaled Doxorubicin for patients with metastatic tumors to the lungs. Clin Cancer Res 13: 1246-1252.

Pilcer G, \& Amighi K (2010). Formulation strategy and use of excipients in pulmonary drug delivery. Int J Pharm 392: 1-19.

Purokivi M, Koskela H, \& Kontra K (2013). Determinants of asthma control and quality of life in stable asthma: evaluation of two new cough provocation tests. Clin Respir J 7: 253-260.

Quattrin T, Belanger A, Bohannon NJ, Schwartz SL, \& Exubera Phase IIISG (2004). Efficacy and safety of inhaled insulin (Exubera) compared with subcutaneous insulin therapy in patients with type 1 diabetes: results of a 6-month, randomized, comparative trial. Diabetes Care 27: 2622-2627.

Richards R, Haas A, Simpson S, Britten A, Renwick A, \& Holgate S (1988). Effect of methacholine induced bronchoconstriction on the pulmonary distribution and plasma pharmacokinetics of inhaled sodium cromoglycate in subjects with normal and hyperreactive airways. Thorax 43: 611-616.

Rosenstock J, Franco D, Korpachev V, Shumel B, Ma Y, Baughman R, et al. (2015). Inhaled Technosphere Insulin Versus Inhaled Technosphere Placebo in Insulin-Naive Subjects With Type 2 Diabetes Inadequately 
Controlled on Oral Antidiabetes Agents. Diabetes Care 38: 2274-2281.

Ryerson CJ, Abbritti M, Ley B, Elicker BM, Jones KD, \& Collard HR (2011). Cough predicts prognosis in idiopathic pulmonary fibrosis. Respirology 16: 969-975.

Satia I, Badri H, Al-Sheklly B, Smith JA, \& Woodcock AA (2016). Towards understanding and managing chronic cough. Clin Med (Lond) 16: s92-s97.

Scheinberg P, \& Shore E (2005). A pilot study of the safety and efficacy of tobramycin solution for inhalation in patients with severe bronchiectasis. Chest 127:1420-1426.

Schuster A, Haliburn C, Doring G, \& Goldman MH (2013). Safety, efficacy and convenience of colistimethate sodium dry powder for inhalation (Colobreathe DPI) in patients with cystic fibrosis: a randomised study. Thorax 68: 344-350.

Shim C, \& Williams MH, Jr. (1987a). Cough and wheezing from beclomethasone aerosol. Chest 91:207-209.

Shim CS, \& Williams MH, Jr. (1987b). Cough and wheezing from beclomethasone dipropionate aerosol are absent after triamcinolone acetonide. Ann Intern Med 106: 700-703.

Sommerwerck U, Virella-Lowell I, Angyalosi G, Viegas A, Cao W, \& Debonnett L (2016). Long-term safety of tobramycin inhalation powder in patients with cystic fibrosis: phase IV (ETOILES) study. Curr Med Res Opin 32: 1789-1795.

Sterling GM, \& Batten JC (1969). Effect of aerosol propellants and surfactants on airway resistance. Thorax 24: $228-231$.

Ternesten-Hasseus E, Johansson EL, \& Millqvist E (2015). Cough reduction using capsaicin. Respir Med 109: 27-37.

van den Borst B, Gosker HR, Zeegers MP, \& Schols AM (2010). Pulmonary function in diabetes: A metaanalysis. Chest 138: 393-406.

Velkov T, Abdul Rahim N, Zhou QT, Chan H-K, \& Li J (2015). Inhaled anti-infective chemotherapy for respiratory tract infections: Successes, challenges and the road ahead. Adv Drug Deliv Rev 85: 65-82.

Westerman EM, De Boer AH, Le Brun PPH, Touw DJ, Roldaan AC, Frijlink HW, et al. (2007). Dry powder inhalation of colistin in cystic fibrosis patients: A single dose pilot study. J Cyst Fibros 6: 284-292.

Westerman EM, Le Brun PPH, Touw DJ, Frijlink HW, \& Heijerman HGM (2004). Effect of nebulized colistin sulphate and colistin sulphomethate on lung function in patients with cystic fibrosis: a pilot study. J Cyst Fibros 3: 23-28.

Wex E, \& Bouyssou T (2015). Olodaterol attenuates citric acid-induced cough in naive and ovalbuminsensitized and challenged guinea pigs. PLoS One 10:e0119953.

Widdicombe JG (1995). Neurophysiology of the cough reflex. Eur Respir J 8: 1193.

Williamson IJ, Matusiewicz SP, Brown PH, Greening AP, \& Crompton GK (1995). Frequency of voice problems and cough in patients using pressurized aerosol inhaled steroid preparations. Eur Respir J 8: 590-592.

Wong CH, \& Morice AH (1999). Cough threshold in patients with chronic obstructive pulmonary disease. Thorax 54: 62-64.

Zhou QT, Leung SS, Tang P, Parumasivam T, Loh ZH, \& Chan HK (2015). Inhaled formulations and pulmonary drug delivery systems for respiratory infections. Adv Drug Deliv Rev 85: 83-99.

Zwozdziaka A, Gini M, \& Samek L (2017). Implications of the aerosol size distribution modal structure of trace and major elements on human exposure, inhaled dose and relevance to the PM2.5 and PM10 metrics in a European pollution hotspot urban area J Aerosol Sci 103: 38-52. 

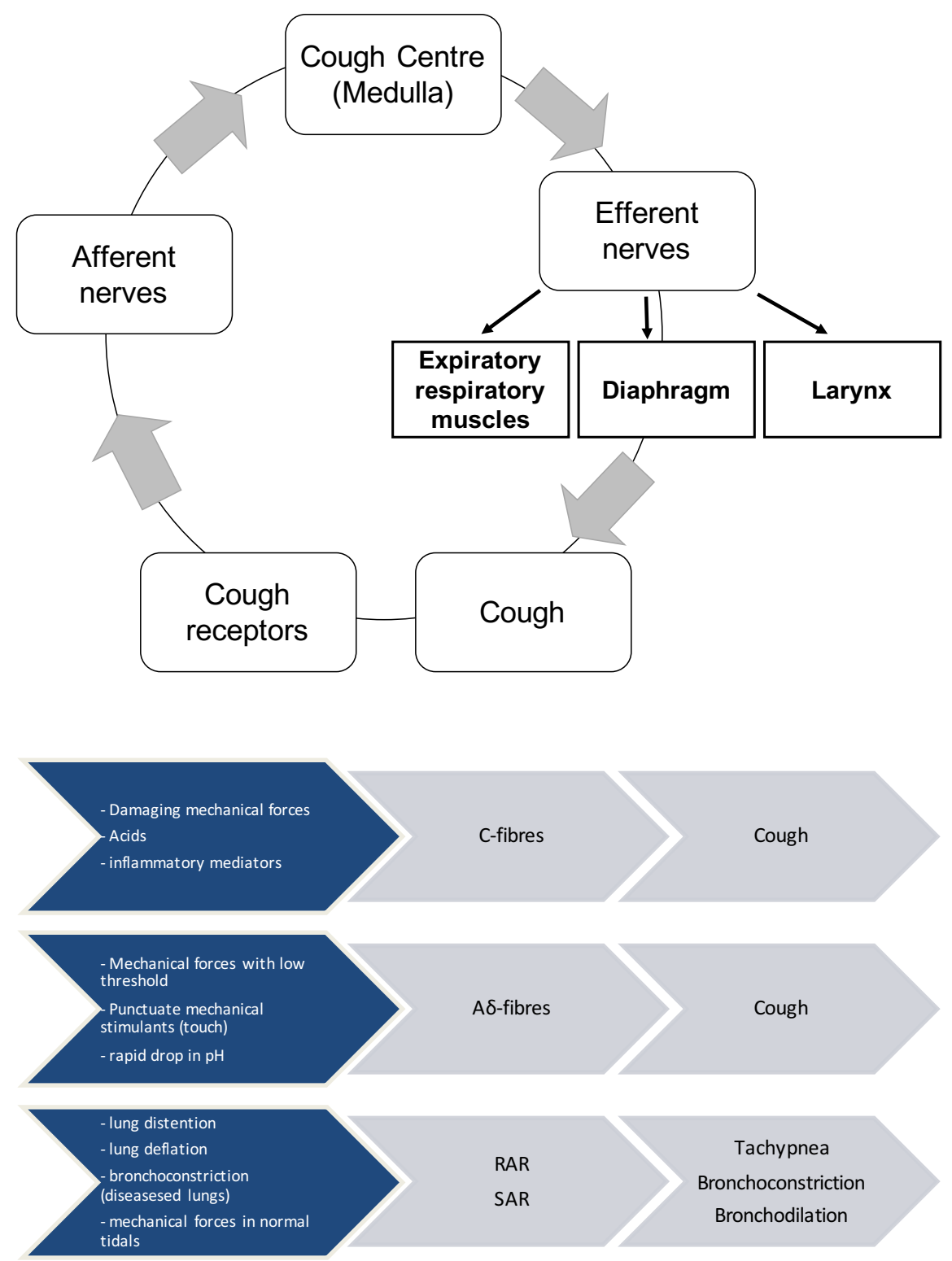


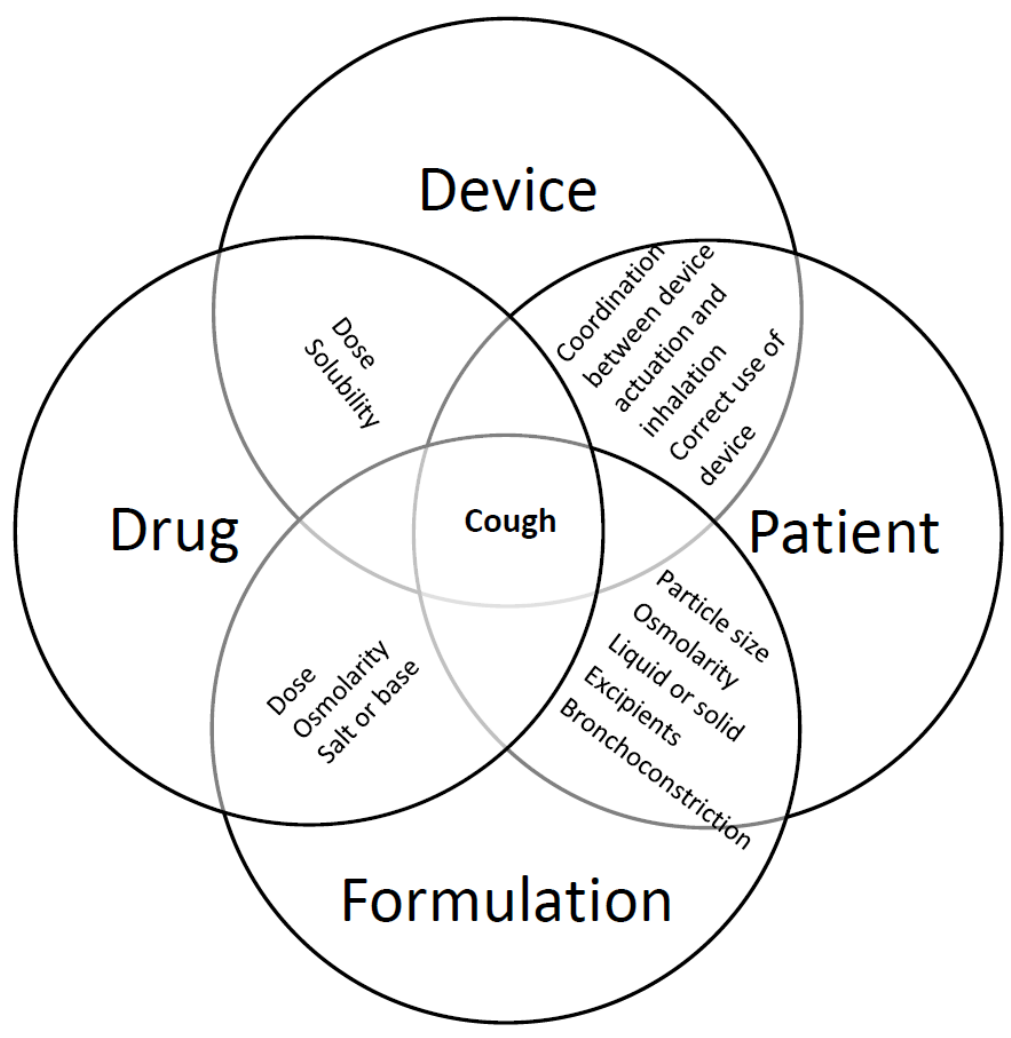

Hosted file

Table 1.docx available at https://authorea.com/users/303830/articles/434080-cough-as-anadverse-effect-for-inhalation-pharmaceutical-products

\section{Hosted file}

Table 2.docx available at https://authorea.com/users/303830/articles/434080-cough-as-anadverse-effect-for-inhalation-pharmaceutical-products 